American J. of Engineering and Applied Sciences 3 (4): 693-698, 2010

ISSN 1941-7020

(C) 2010 Science Publications

\title{
Optimization of the Geometrical Parameters of a Solar Bubble Pump for Absorption-Diffusion Cooling Systems
}

\author{
${ }^{1}$ N. Dammak, ${ }^{1}$ B. Chaouachi, ${ }^{1}$ S. Gabsi and ${ }^{2}$ M. Bourouis \\ ${ }^{1}$ Department of Chemical Engineering and Processes, \\ National School of Engineers of Gabes (E.N.I.G), \\ Omar Ibn El Khattab Street-6029 Gabes, Tunisia \\ ${ }^{2}$ Department of Mechanical Engineering, University Rovira iVirgili, \\ Avenida dels Països Catalans, 26, 43007 Tarragona, Spain
}

\begin{abstract}
Problem statement: The objective of this study was to optimize the geometrical parameters of a bubble pump integrated in a solar flat plate collector. Approach: This solar bubble pump was part of an ammonia/water/helium $\left(\mathrm{NH}_{3} / \mathrm{H}_{2} \mathrm{O} / \mathrm{He}\right)$ absorption-diffusion cooling system. Results: An empirical model was developed on the basis of momentum, mass, material equations and energy balances. The mathematical model was solved using the simulation tool "Engineering Equation Solver (EES)". Conclusion/Recommendations: Using metrological data from Gabes (Tunisia) various parameters were geometrically optimized for maximum bubble pump efficiency which was best for a bubble pump tube diameter of $6 \mathrm{~mm}$, a tube length of $1.5 \mathrm{~m}$, an inclination to the horizontal between 30 and $50^{\circ}$ of the solar flat plate collector and a submergence ratio between 0.2 and 0.3 .
\end{abstract}

Key words: Bubble pump, absorption-diffusion cycle, ammonia-water, solar cooling

\section{INTRODUCTION}

The influence of the cycle configuration on the performance of an absorption-diffusion cooling system has been investigated by various researchers. Zohar et al. (2007) compared the performance of two fundamental configurations of a Diffusion Absorption Refrigeration (DAR) cycle, with and without condensate sub-cooling prior to the evaporator entrance. They analyzed the performances of the two cycles by computer simulations and concluded that the DAR cycle without condensate sub-cooling, at higher evaporator temperature of about $15^{\circ} \mathrm{C}$, shows higher COP of about $14-20 \%$ compared with the DAR cycle with condensate sub-cooling. Subsequently, they developed thermodynamic models for three generator and bubble pump configurations (Zohar et al., 2008): That is, (a) heat input into the rich solution without heat transfer to the poor solution; (b) heat input into the rich solution with heat transfer to the poor solution flowing in the annular space and (c) heat input into the rich solution through the poor solution, thus also desorbing refrigerant from the poor solution, with heat transfer to the poor solution in the annular space. The performance of three DAR systems, which differ in their generator and bubble pump configuration, was studied numerically. The results showed that for the same heat input, the second configuration desorbed the highest amount of refrigerant and the first configuration desorbed the lowest amount. The third configuration proved to be less efficient in terms of COP than the second configuration. The first configuration gave the lowest performance, although heat was supplied directly to the rich solution.

Shelton and Stewart (2002) developed a model for a bubble pump using two-phase flow correlations to establish the optimum design parameters. The experimental results showed that its performance was not sensitive to the length of the lift tube; however it was highly dependant on the submergence ratio. Koyfman et al. (2003) conducted experimental research on the bubble pump performance. A solution mixture of organic solvent and hydrochlorofluorocarbon refrigerant was used as the working fluid. It was found that the motive head is one of the parameters that most influences the bubble pump performance. Changing the motive head by $10 \%$ changed the mass flow rates by about $40 \%$. The authors concluded that a low motive head provides higher refrigerant flow rates and, therefore, a higher cooling capacity. The maximum average generator temperature was below $90^{\circ} \mathrm{C}$. Hence, they concluded that a complete diffusion absorption

Corresponding Author: N. Dammak, Department of Chemical Engineering and Processes,

National School of Engineers of Gabes (E.N.I.G), Omar Ibn El Khattab Street-6029 Gabes, Tunisia 
refrigerating system that operates with organic solvents and hydrochlorofluorocarbon refrigerants may be driven by low temperature heat sources, such as solar thermal energy or waste heat. Chen et al. (1996) attempted to improve the current cycle performance of the Diffusion Absorption Refrigerator (DAR). They recommended using waste heat from the rectifier to preheat the weak solution leaving the absorber. A new Generator With Heat Exchanger (GWHX) was designed, built and tested. The test results of the DAR with GWHX were compared with baseline tests. The new generator design increased the cooling COP by as much as $50 \%$ more than the baseline tests while the cooling capacity remained constant. Srikhirin and Aphornratana (2002) reported an experimental study of a DAR cycle. The system was tested with heat input values between 1000 and $2500 \mathrm{~W}$ at a helium pressure of 6.1 bars. The system cooling capacities were found to be between 100 and $180 \mathrm{~W}$ with a COP between 0.09 and 0.15. Chaouachi and Gabsi (2007) designed and simulated an absorption diffusion refrigerator using solar energy for domestic use. They concluded that the COP would be best when the system was operated at a low generator temperature and high pressure. On the other hand, the numerical values of COP were still low and depended on the power of the solar bubble pump.

In the present study, the new design of the bubble pump proposed by Chaouachi and Gabsi (2007) was optimized. A model for a system consisting of a bubble pump integrated in a solar flat plate collector was developed and used to optimize the geometrical parameters of the solar bubble pump of an ammonia/water/helium absorption-diffusion cooling system.

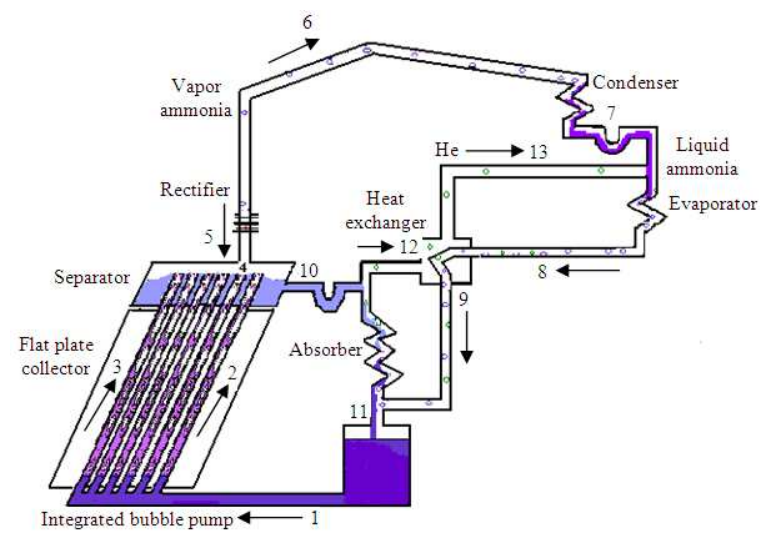

Fig. 1: Schematic view of the absorption diffusion machine
Solar diffusion-absorption cycle: Figure 1 shows a schematic configuration of the solar heat driven ammonia/water/helium diffusion-absorption cooling system, consisting of a bubble pump, an absorber, a condenser, an evaporator, a rectifier, a heat exchanger and a reservoir. In this configuration the bubble pump tubes are integrated in the solar flat plate collector.

Ammonia vapor is separated from the rich solution (1) in the separator. The vapor (2) then rises inside the bubble pump and flows through the rectifier where water vapor condenses (5) to join the weak solution (3). The pure ammonia (6) flows to the condenser, condenses (7) and flows to the evaporator. At the evaporator entrance the partial pressure of the ammonia liquid (7) drops because it mixes with the helium and ammonia vapor (13) from the absorber, which causes the refrigerant to evaporate. The ammonia-helium mixture (8) flowing in parallel through the shell side of the evaporator/gas heat exchanger enters the absorber and flows upward in counter flow to the weak solution entering the absorber at the top (10). In the absorber, the ammonia vapor is absorbed by the weak solution and the solution obtained flows down into the reservoir (11). Helium and ammonia residuals (12) flow toward the evaporator.

\section{MATERIALS AND METHODS}

An empirical model was developed on the basis of momentum, mass, material equations and energy balances. The mathematical model was solved using the simulation tool "Engineering Equation Solver (EES)".

Theoretical analyses: The following equations are based on Fig. 2. Frictional losses at the entrance to the tubes are considered insignificant and the steady state flow is established.

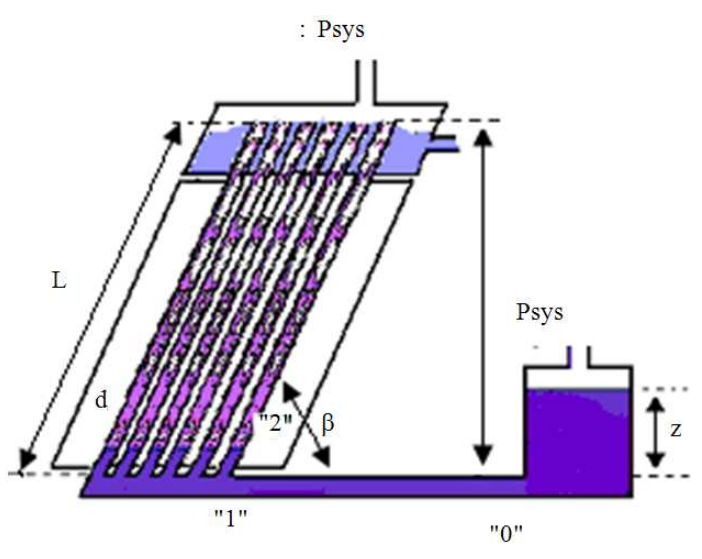

Fig. 2: Integrated solar bubble pump 
Momentum equation from $\mathrm{P}_{\text {sys }}$ to " 0 ", from " 0 " to "1" and from state "1 to 2" yield (Shelton and Stewart, 2002):

$$
\mathrm{P}_{2}-\mathrm{P}_{\mathrm{sys}}=\rho_{1} \mathrm{gz}+\frac{\mathrm{G}_{\mathrm{t}}^{2}}{\rho_{1}}\left(\frac{1}{2}-\frac{\mathrm{d}_{0}^{2}}{\mathrm{~d}_{2}^{2}}\right)
$$

Where:

$$
\mathrm{G}_{\mathrm{t}}=\mathrm{v}_{0} \rho_{1}
$$

Momentum equation from $\mathrm{P}_{\text {sys }}$ to "2" gives (vertical bubble pump) (Shelton and Stewart, 2002):

$$
\mathrm{P}_{2}=\mathrm{P}_{\mathrm{sys}}+\rho_{\mathrm{m}} \cdot \mathrm{g} \cdot \mathrm{L}+\mathrm{f}_{\mathrm{tp}} \frac{\rho_{\mathrm{m}} \cdot v^{2}}{2} \cdot \frac{\mathrm{L}}{\mathrm{d}_{2}}
$$

For a bubble pump integrated in a solar flat plate collector, Eq. 3 gives:

$\mathrm{P}_{2}=\mathrm{P}_{\mathrm{sys}}+\rho_{\mathrm{m}} \cdot \mathrm{g} \cdot \mathrm{L} \sin (\beta)+\mathrm{f}_{\mathrm{tp}} \frac{\rho_{\mathrm{m}} \cdot v^{2}}{2} \cdot \frac{\mathrm{L}}{\mathrm{d}_{2}}$

Where:

$$
\mathrm{f}_{\mathrm{tp}}=\mathrm{k}\left(\frac{\rho_{\text {poor }} \nu_{\text {poor }} \mathrm{d}_{2}}{\mu_{\text {poor }}}\right)^{\mathrm{s}}
$$

$\mathrm{K}$ and $\mathrm{s}$ are the BLASIUS factor $(\mathrm{K}=0.316$ and $s=-0.25)$ (Shelton and Stewart, 2002)

Specific mass flow rate of the rich solution:

$\mathrm{G}_{\mathrm{tot}}=v \cdot \rho_{\mathrm{m}}$

Because of $\rho_{\text {poor }} \gg>\rho_{\text {vapour }}$, the velocity of the poor solution is given by:

$$
v_{\text {poor }}=\frac{G_{\text {tot }}}{\rho_{\text {poor }}}
$$

$$
\text { Equation } 1 \text { and } 4 \text { gives }\left(\text { neglecting } \frac{\mathrm{G}_{t}^{2}}{\rho_{1}}\left(\frac{1}{2}-\frac{\mathrm{d}_{2}^{2}}{\mathrm{~d}_{0}^{2}}\right)\right) \text { : }
$$$$
G_{\text {tot }}=\left(\left(\rho_{\mathrm{g} g} \mathrm{~g}-\rho_{\mathrm{m}} \mathrm{gL} \sin (\beta)\right)\left(\mathrm{K}\left(\frac{\mathrm{d}_{2}}{\mu_{\mathrm{poor}}}\right)^{5} \frac{1}{2 \rho_{\mathrm{m}}} \frac{\mathrm{L}}{\mathrm{d}_{2}}\right)^{-1}\right)^{1.75}
$$

The submergence ratio is defined as:
$\operatorname{sub}=\frac{\mathrm{z}}{\mathrm{H}}$

and:

$\mathrm{H}=\mathrm{L} \sin (\beta)$

For a bubble pump using $n_{t}$ tubes, the specific mass flow rate is given by:

$\dot{\mathrm{m}}_{1}=\frac{1}{4} \mathrm{ntG}_{\text {too }} \pi \cdot \mathrm{d}_{2}^{2}$

Mass energy balance at the generator:

$\dot{\mathrm{m}}_{1}=\dot{\mathrm{m}}_{2}+\dot{\mathrm{m}}_{3}$

$\dot{\mathrm{m}}_{1} \mathrm{x}_{1}=\dot{\mathrm{m}}_{2} \mathrm{y}_{2}+\dot{\mathrm{m}_{3} \mathrm{x}_{3}}$

$\mathrm{Q}_{\mathrm{g}}=\dot{\mathrm{m}}_{2} \mathrm{~h}_{2}+\dot{\mathrm{m}}_{3} \mathrm{~h}_{3}-\dot{\mathrm{m}}_{1} \mathrm{~h}_{1}$

Useful solar heat (Sukhatme, 1997; Kalogirou, 2006):

$\mathrm{Q}_{\mathrm{u}}=\mathrm{A}_{\mathrm{c}}\left(\phi-\mathrm{U}_{\mathrm{L}}\left(\mathrm{T}_{\mathrm{f}}-\mathrm{T}_{\mathrm{a}}\right)\right.$

Liquid, gas and global efficiency are defined as:

The gas efficiency: $E_{G}=\frac{\dot{m_{2}}}{Q_{u}}$

The liquid efficiency $: E_{L}=\frac{\dot{m}_{3}}{Q_{u}}$

The globalefficiency: $\mathrm{E}_{\mathrm{gl}}=\mathrm{E}_{\mathrm{G}} \cdot \mathrm{E}_{\mathrm{L}}$

Calculation procedure: The basic input data of the system shown schematically in Fig. 2 were: condenser temperature $\left(\mathrm{T}_{\mathrm{c}}=45^{\circ} \mathrm{C}\right)$, absorber temperature $\left(\mathrm{T}_{\mathrm{ab}}=\right.$ $\left.45^{\circ} \mathrm{C}\right)$, evaporator temperature $\left(\mathrm{T}_{\mathrm{ev}}=15^{\circ} \mathrm{C}\right)$. The calculation sequence was as follows:

- Calculate solar intensity ( $\phi$ ) (Liu and Jordan, 1960; 1961)

- Calculate the Pressure of the system $\left(\mathrm{P}_{\text {sys }}\right)$ using the condenser temperature

- Determine the rich solution concentration $\left(\mathrm{x}_{1}\right)$ using the P-T-x relationship for the ammonia-water solution at equilibrium (Zohar et al., 2005) 
- $\quad$ Adjust the outlet temperature of the generator $\left(\mathrm{T}_{\mathrm{g}}\right)$ until it satisfies the equality between the energy balance of the generator $\left(\mathrm{Q}_{\mathrm{g}}\right)$ and the useful solar heat $\left(\mathrm{Q}_{\mathrm{u}}\right)$ using Eq. 14 and 15 (since the useful heat available from the collector is transferred to the rich solution in the generator)

- Determine the poor solution concentration $\left(\mathrm{x}_{3}\right)$ using the P-T-x relationship (Zohar et al., 2005)

- Calculate the refrigerant concentration $\left(\mathrm{y}_{2}\right)$. The $\mathrm{NH}_{3} \mathrm{H}_{2} \mathrm{O}$ procedure called from EES provides the thermodynamic properties of ammonia water mixtures in saturated conditions

- Calculate the mass flow rate of rich solution $\left(\mathrm{m}_{1}\right)$, poor solution $\left(\mathrm{m}_{3}\right)$ and the mass flow rate of refrigerant $\left(\mathrm{m}_{2}\right)$, using Eq. 12 and 13

- Calculate the gas efficiency, the liquid efficiency and the global efficiency (Eq. 16-18)

\section{RESULTS AND DISCUSSION}

Figure 3-9 showed the most significant results obtained by simulation with the Equation Engineering Solver (EES) software.

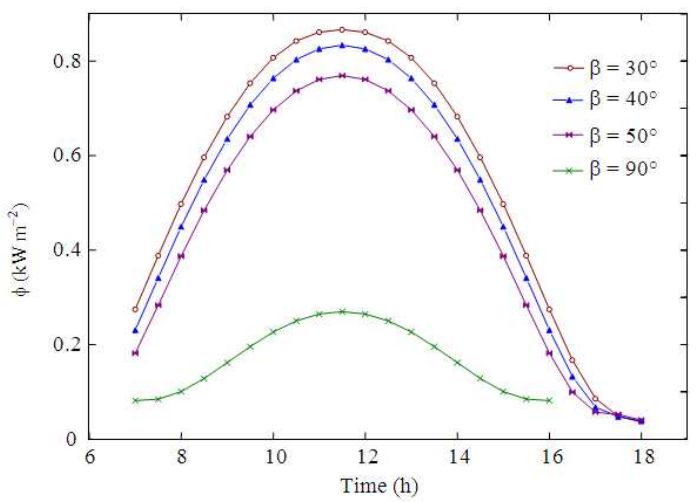

Fig. 3: Solar intensity Vs time (day 01/08)

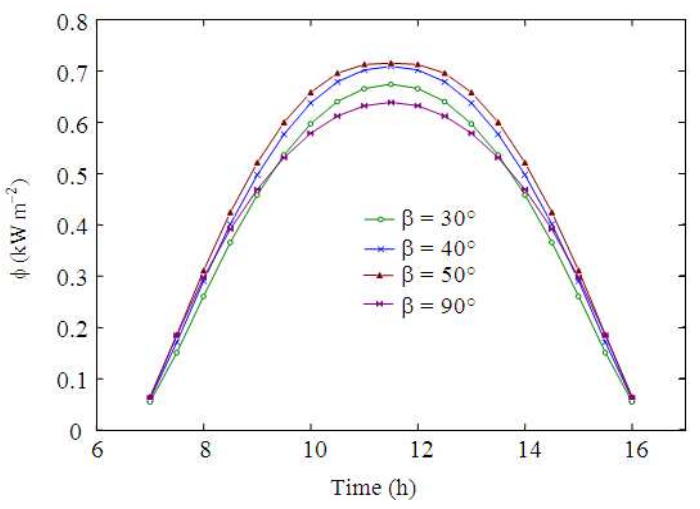

Fig. 4: Solar intensity Vs time (day 01/01)

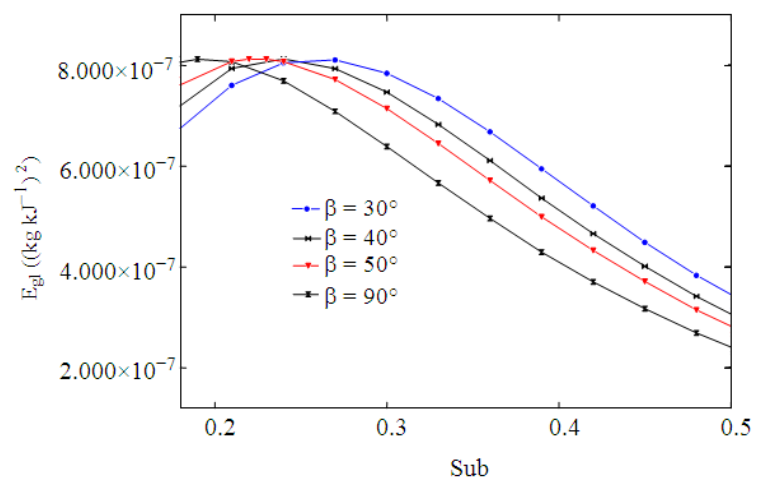

Fig. 5: Global efficiency Vs submergence ratio $\left(\phi_{\mathrm{av}}=0.6 \mathrm{~kW} \mathrm{~m}^{-2}, \mathrm{~L}=1.5 \mathrm{~m}\right.$ and $\mathrm{d}=6 \mathrm{~mm}$ (month-8-))

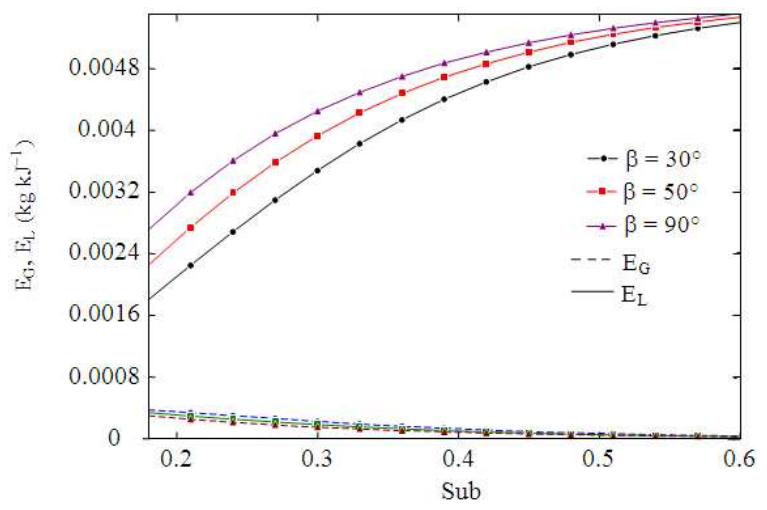

Fig. 6: Liquid efficiency and gas efficiency Vs submergence ratio $\left(\phi_{\mathrm{av}}=0.6 \mathrm{~kW} \mathrm{~m}^{-2}, \mathrm{~L}=1.5\right.$ $\mathrm{m}$ and $\mathrm{d}=6 \mathrm{~mm}$ (month-8- ))

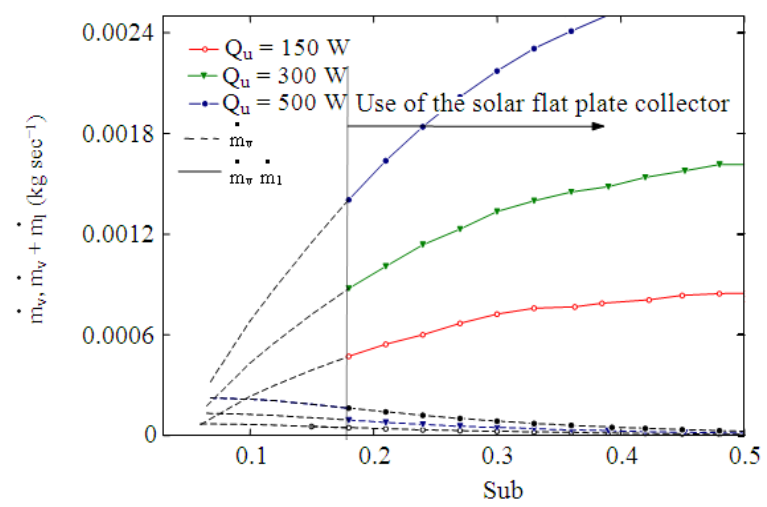

Fig. 7: Mass flow rate of generated vapour and pumped liquid Vs submergence ratio $\left(\phi_{\max }=0.83 \mathrm{~kW} \mathrm{~m}^{-2}\right.$ (month-8- )) 


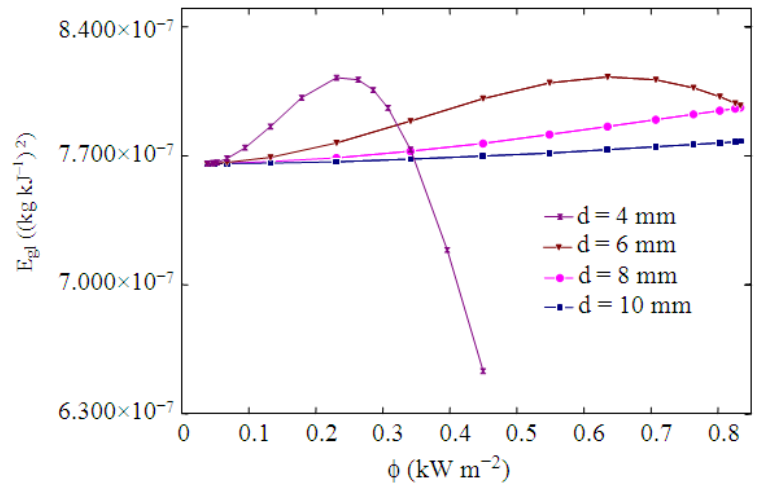

Fig. 8: Global efficiency Vs solar intensity at different tube diameters. $\left(\mathrm{L}=1.5 \mathrm{~m}\right.$, sub $_{\mathrm{av}}=0.25, \beta_{\mathrm{av}}=40^{\circ}$ (month-8-))

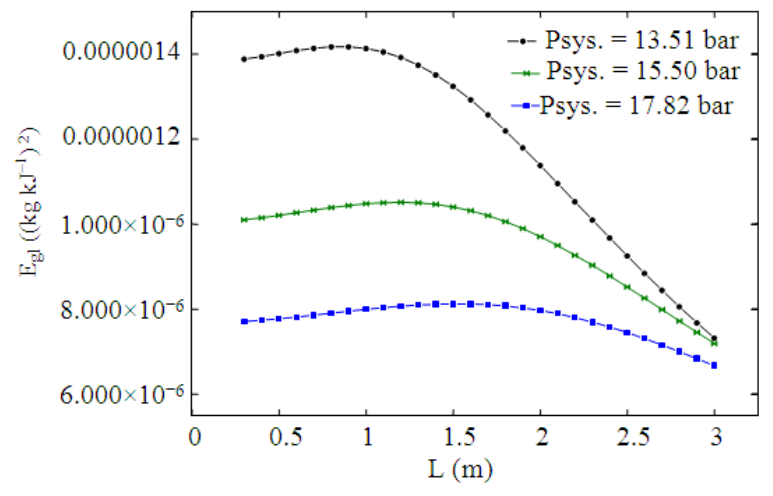

Fig. 9: Global efficiency Vs tube length $\left(\mathrm{sub}_{\mathrm{av}}=0.25\right.$, $\beta_{\mathrm{av}}=40^{\circ}$ and $\mathrm{d}=6 \mathrm{~mm}$ (month-8-))

Figure 3 and 4 illustrate the hourly variation of solar intensity obtained by the Liu and Jordan (1960; 1961) model for the region of Gabes in Tunisia. Solar intensity was maximum at 11.30 when the inclination angle of the solar flat plate collector varied between 30 and $50^{\circ}$. This can be explained by the fact that in winter, when the trajectory of the sun in the sky is low, the inclination angle must be high. However, it is recommended for the inclination angle to be low during the summer months when the sun in the sky is higher (Solar radiation is perpendicular to the collector).

The variation of the global efficiency, gas efficiency and liquid efficiency of the solar bubble pump with submergence ratio at different solar flat plate inclination angles of the solar collector is shown in Fig. 5 and 6. For inclination angles of the solar flat plate collector between 30 and $50^{\circ}$, the optimal submergence ratio varied in the range 0.2-0.3.

As can be seen in Fig. 5, global efficiency is sensitive to the submergence ratio. Two submergence ratio ranges can be identified. In the first range global efficiency increases when the submergence ratio increases. This can be explained by the fact that any increase in the submergence ratio increases the mass flow rate of the rich solution. Hence, the mass flow of the pumped liquid increases and the mass flow of the generated vapor decreases (Fig. 6) so the global efficiency (defined as $\mathrm{E}_{\mathrm{G}} . \mathrm{E}_{\mathrm{L}}$ ) increases. At high submergence ratios (after reaching the maximum), however, the global efficiency decreases because the mass flow rate of the rich solution increases causing the mass flow rate of the refrigerant to drop sharply (Fig. 6) compared to the mass flow rate of the poor solution.

Under the operating conditions $\mathrm{T}_{\mathrm{ab}}=45^{\circ} \mathrm{C}$, $\mathrm{T}_{\mathrm{c}}=45^{\circ} \mathrm{C}, \mathrm{T}_{\mathrm{ev}}=15^{\circ} \mathrm{C}, \beta_{\mathrm{av}}=40^{\circ}, \quad \mathrm{sub}_{\mathrm{av}}=0.25$, $\phi=0.83 \mathrm{~kW} \mathrm{~m}^{-2}, \mathrm{n}_{\mathrm{t}}=6$ and $\mathrm{A}_{\mathrm{c}}=3.8 \mathrm{~m}^{2}$, the cooling capacity of the diffusion absorption machine was equal to $450 \mathrm{~W}$.

In order to determine the minimal values of the submergence ratio, the variation in the mass flow rate of the generated vapor and pumped liquid vs. submergence ratio has been illustrated in Fig. 7. The intersection of the curve giving the mass flow rate of the generated vapor and the curve giving both the generated and pumped solution gives the minimal submersion ratio $\left(\dot{\mathrm{m}}_{\mathrm{v}}+\dot{\mathrm{m}}_{\mathrm{l}}=\dot{\mathrm{m}}_{\mathrm{v}}\right.$ gives $\left.\dot{\mathrm{m}}_{1}=0\right)$. Figure 7 shows that the solar flat plate collector cannot be used with submersion values under 0.18 (the temperature required in the generator is too high).

Figure 8 illustrates the variation of global efficiency vs. solar intensity for tube diameters between 4 and $6 \mathrm{~mm}$ at $\mathrm{L}=1.5 \mathrm{~m}$, $\operatorname{sub}_{\mathrm{av}}=0.25$ and $\beta_{\mathrm{av}}=40^{\circ}$. Performance is most efficient when the bubble pump tube diameters are equal to $6 \mathrm{~mm}$ (corresponding to $\phi_{\mathrm{av}}$ $=0.6 \mathrm{~kW} \mathrm{~m}^{-2}$ ). This can be explained as follows: If the bubble pump tube diameters are over $6 \mathrm{~mm}$ the flow rate of the rich solution increases when the heat input is constant. Thus, the poor solution flow rate increases and the refrigerant flow rate decreases, resulting in a decrease in the global efficiency.

Figure 9 shows that the system pressure has considerable influence on the global efficiency. This is because the decrease in the system pressure (decrease in the absorber and condenser temperature) improves absorption and the mass flow rate of the rich solution increases which increases global efficiency.

Global efficiency values for a system pressure $\mathrm{P}_{\text {sys }}$ $=17.82 \mathrm{bar}\left(\mathrm{T}_{\mathrm{c}}=45^{\circ} \mathrm{C}\right)$ were highest at a tube length of $1.5 \mathrm{~m}$ (Fig. 9). When the tube length increases, the collector area increases so more heat is supplied to the rich solution witch in turn increases the global efficiency. When the tubes are too long (over $2 \mathrm{~m}$ ), the 
submergence ratio (defined as sub $=\frac{\mathrm{Z}}{\mathrm{H}}$, where $\mathrm{H}=\mathrm{L} \sin \beta$ ) decreases. Hence, the mass flow rate of the rich solution and the global efficiency decrease.

\section{CONCLUSION}

A model of an integrated solar bubble pump was developed. Various parameters were geometrically optimized for maximum global efficiency by computer simulation. It was found that efficiency is best for a bubble pump tube diameter of $6 \mathrm{~mm}$, a tube length of $1.5 \mathrm{~m}$, an inclination angle of the solar flat plate collector between 30 and $50^{\circ}$ and a submergence ratio in the range $0.2-0.3$. In order to determine the minimal values of the submergence ratio, the mass flow rate variation of the generated vapor and pumped liquid vs. submergence ratio at different values of useful heat was studied. It was found that when the submersion ratio was too low, the solar flat plate collector could not be used.

\section{ACKNOWLEDGEMENT}

The researchers gratefully acknowledge the Spanish Ministry of Science and Innovation for its financial support (ENE2006-15250).

\section{REFERENCES}

Chaouachi, B. and S. Gabsi, 2007. Design and simulation of an absorption diffusion solar refrigeration unit. Am. J. Applied Sci., 4: 85-88. DOI: $10.3844 / .2007 .85 .88$

Chen, J., K.J. Kim and K.E. Herold, 1996. Performance enhancement of a diffusion-absorption refrigerator. Int. J. Refrig., 19: 208-218. DOI: 10.1016/01407007(96)87215-X

Kalogirou, S.A., 2004. Solar thermal collectors and applications. Prog. Energy Combust. Sci., 30: 231-295. DOI: 10.1016/j.pecs.2004.02.001

Koyfman, A., M. Jelinek, A. Levy and I. Borde, 2003. An experimental investigation of bubble pump performance for diffusion absorption refrigeration system with organic working fluids. Applied Therm. Eng., 23: 1881-1894. DOI: 10.1016/S13594311(03)00162-5
Liu, B.Y.H. and R.C. Jordan, 1960. The interrelationship and characteristic distribution of direct, diffuse and total solar radiation. Sol. Energy, 4: 1-19. DOI: 10.1016/0038092X(60)90062-1

Liu, B. and R.C. Jordan, 1961. Daily insolation on surfaces tilted towards the equator. ASHRAE Trans., $\quad 10$ : 53-53. http://www.osti.gov/energycitations/product.biblio. jsp?osti_id=5047843

Srikhirin, P. and S. Aphornratana, 2002. Investigation of a diffusion absorption refrigerator. Applied Therm. $\quad$ Eng., 22: 1181-1193. http://www.thaiscience.info/Article\%20for\%20Tha iScience/Article/3/Ts-

$3 \% 20$ investigation $\% 20$ of $\% 20 \mathrm{a} \% 20$ diffusion $\% 20 \mathrm{ab}$ sorption\%20refrigerator.pdf

Sukhatme, S.P., 1997. Solar Energy: Principles of Thermal Collection and Storage. 2nd Edn., McGraw-Hill Inc., USA., ISBN: 10: 0074624539, pp: 464.

Shelton, S.V. and S.W. Stewart, 2002. Bubble pump design for single pressure absorption refrigeration cycles. ASHRAE Trans., 108: 1-10.

Zohar, A., M. Jelinek, A. Levy and I. Borde, 2005. Numerical investigation of a diffusion absorption refrigeration cycle. Int. J. Refrig., 28: 515-525. DOI: 10.1016/j.ijrefrig.2004.11.003

Zohar, A., M. Jelinek, A. Levy and I. Borde, 2007. The influence of diffusion absorption refrigeration cycle configuration on the performance. Applied Therm. Eng., 27: 2213-2219. DOI: 10.1016/j.applthermaleng.2005.07.025

Zohar, A., M. Jelinek, A. Levy and I. Borde, 2008. The influence of the generator and bubble pump configuration on the performance of Diffusion Absorption Refrigeration (DAR) system. Int. J. Refrig. $\quad 30$ : $\quad 1-8 . \quad$ DOI: 10.1016/j.ijrefrig.2008.01.009 